\title{
DERECHOS Y PRIVILEGIOS DE LOS MUDÉJARES DE LAS TIERRAS ALICANTINAS EN LA DOCUMENTACIÓN DE JAIME II
}

\author{
Mª Magdalena MARTÍNEZ ALMIRA
}

El interés suscitado, recientemente, en torno al modus vivendi de los mudéjares, tras la irrupción de cristianos en las tierras andalusíes, ha dado lugar a aportaciones valiosas que han sacado a la luz el entramado jurídico de una comunidad obligada a readaptar sus ancestrales tradiciones a las exigencias derivadas de una convivencia pacífica.

La abundante legislación medieval promulgada por los monarcas castellanos y aragoneses sigue siendo fuente inagotable para historiadores y juristas en orden al conocimiento de las instituciones jurídicas reguladoras de la economía, sociedad y política de las comunidades mudéjares.

Ahora bien, en el ámbito de la Corona de Aragón los estudios realizados han tenido, por el momento, como principal protagonista a Jaime I quien, como conquistador de la mayor parte de las tierras catalano-aragonesas, hubo de iniciar la tarea de adecuación normativa e institucional a las exigencias de las gentes que poblablan estos lugares'. Pero si difícil hubo de ser la labor iniciada por el Conquistador, no quedó exenta de complicaciones la política de relaciones intercomunitarias que, en la misma

1 En relación al respeto a las instituciones véase la importante aportación documental relativa a las comunidades mudéjares del Reino de Valencia, siendo de obligada consulta la documentación aportada por BURNS en su obra Socitat i documentaciò en el Regnat de València. Diplomatarium I: Introducciò, vol. 1, 1a ed. Valencia, 1988; en relación con las cartas de población otorgadas a las comunidades musulmanas de los pueblos circundantes a Valencia véase FEBRER ROMAGUERA, M.N., Cartas pueblas de las morerías valencianas y documentación complementaria, Zaragoza, 1991; $\mathrm{HUICI}$ MIRANDA, A. y CABANES PECOURT, Ma.D., Documentos de Jaime / de Aragón, Valencia, 1976, 2 vols. 
línea, llevaron a término sus sucesores y, en concreto, la del monarca Jaime II; éste, acosado por las vicisitudes de la política castellana, de los reyes de Granada y de los de Berbería se vio obligado a realizar grandes esfuerzos legislativos para seguir manteniendo el ideal de la unidad del Reino.

Pero al lector interesado en el análisis del organigrama jurídico concerniente a las comunidades mudéjares durante el reinado de Jaime II no se le ofrecen obras unitarias, si bien día a día los trabajos monográficos al respecto son cada vez mayores. El objeto de este trabajo es configurar un esquema sintético de las instituciones jurídicas que, a través de los documentos conservados, constate el respeto a determinados derechos inherentes a los mudéjares de Sharq Al-Andalus. Este marco institucional permitirá completar el panorama jurídico relativo a los musulmanes y que hasta el día de hoy no ha sido abordado de forma global.

\section{I. ÁMBITO ESPACIAL Y TEMPORAL EN LA CONFIGURACIÓN DE LOS DERE- CHOS Y PRIVILEGIOS}

La política desarrollada por Jaime II en favor de los mudéjares que permanecieron en territorio levantino, y concretamente en las tierras de Alicante, obedece en primer lugar, a una serie de circunstancias espaciales y temporales motivadas por el respeto a la política del rey castellano Alfonso $X$ el Sabio. Los deseos expansionistas de los monarcas castellanos y aragoneses, que en cada momento ocuparon el poder, encontraron un vehículo favorable en las necesidades que apremiaban a los contigentes poblacionales asentados en los distintos territorios. El objeto principal de la política real fue intentar ganar adeptos a causas comunes, como el bienestar de los súbditos y la paz en sus territorios; estas causas fueron enarboladas como banderas contra la intransigencia religiosa. Es por ello que, en muchas ocasiones, los monarcas, de una $\mathrm{u}$ otra corona, pretendieran ganar el favor de las pequeñas comunidades religiosas a partir de concesiones graciosas con las que conseguir el apoyo de facto para acometer nuevas empresas reconquistadoras. El resultado favorable de esta política fue siempre premiado con el reconocimiento y la concesión de derechos personales y patrimoniales. De este modo se garantizaba el mantenimiento de privilegios reales que, por razón de igualdad y equiparación entre comunidades distintas, se poseian desde antaño.

Todas estas consideraciones quedan de manifiesto en la documentación del monarca Jaime II; éste, desde 1296 hasta la fecha de su muerte, promulga numerosos documentos ratificando y confirmando los derechos de las pequeñas comunidades confesionales murcianas que habían obtenido. Por ello se hace necesario la remisión a los documentos de Alfonso X el Sabio, del Infante don Sancho y de Jaime I para tierras levantinas en general y alicantinas en particular; todos ellos fueron artífices del panorama legistativo heredado por Jaime II para la población mudéjar.

Así pues el trazado del esquema institucional en torno a unos ejes espaciales y temporales de dicha legislación precisa determinar con respecto a este segundo elemento, el tiempo, el momento exacto en que se inicia la política legislativa destinada 
a asegurar la pacífica convivencia entre musulmanes y cristianos. En este sentido podría tomarse como hito inicial el año en que tiene lugar la donación, reconocida publicamente, del reino de Murcia por Alfonso de la Cerda en 1296; ésta actuación política justifica la presencia del monarca en una amplia zona del levante peninsular desde Alicante, pasando por Orihuela, hasta llegar a las tierras de Lorca y Mula².

Pero durante el reinado de Jaime II el Justo, se suceden toda una serie de acontecimientos que irrumpen en el desarrollo lineal de la política del monarca; es, por tanto, con la sentencia de Torrellas, en 1304, cuando se establecen definitivamente los límites espaciales y temporales de la política de Jaime II en la Gobernación y posterior Procuración de Orihuela ${ }^{3}$ y tierras alicantinas ${ }^{4}$; mediante esta política, escasamente innovadora y mayoritariamente conservadora, como se retoman los antiguos derechos de los musulmanes alicantinos, adaptándolos a las nuevas exigencias del momento político y social.

\section{SENTIDO DE LOS TÉRMINOS DERECHOS Y PRIVILEGIOS SEGÚN LOS DO- CUMENTOS REFERIDOS A LA POBLACIÓN MUDÉJAR}

Uno de los primeros aspectos a destacar es el carácter totalizador que los términos derechos y privilegios poseen en relación a las personas integradas en las comunidades islámicas levantinas. Porque, en efecto, estos vocablos comprenden una serie de derechos inherentes a la persona y a su patrimonio, pudiendo diferenciar, a través de las fuentes, las instituciones jurídicas que se pretenden salvaguardar de forma legítima.

Debe advertirse, sin embargo, que son escasos los documentos de Jaime II en los que aparece el término derechos; más bien los derechos, en sentido genérico, se concretan en la documentación a partir del reconocimiento de privilegios, franquicias, libertades, donaciones, mercedes, buenos usos y costumbres en favor de los mudéjares. Así pues puede constatarse desde el momento en que el monarca aragonés hace acto de presencia en territorio castellano; tal ocurre en el documento fechado el 11 de mayo de 1296 en favor de los habitantes de Orihuela ${ }^{5}$, donde estos derechos, sin

2 Véase sobre la presencia del rey Jaime II en tierras murcianas y las vicisitudes de su campaña: Historia de la Región Murciana, t. III, Murcia (1980), pp. 377-384.

3 La consiguiente formación de la gobernación de Orihuela bajo dominio aragonés supone la configuración de un nuevo marco espacial en el que quedaban incluídas las tierras alicantinas. Sobre este aspecto remítase el lector a TORRES FONTES, J., "Los mudéjares murcianos en el siglo XIIl", en Murgetana, 17 (1961), p. 79; RODRÍGUEZ LLOPIS, M., «La expansión territorial castellana sobre la Cuenca del Segura (1235-1325)", en Miscelánea Medieval Murciana, XIl, Murcia (1985), pp. 113114.

4 Las provisiones reales de los años 1296 y 1297 y el Acta de anexión o carta magna reativa a la incorporación formal del Camp d'Alacant al reino de Valencia en 1308. Puede verse J.M. del ESTAL, "Anexión del Campo d'Alacant al reino de Valencia. Por Jaime II de Aragón (1308)" (Comunicación al I Congres d'Estudis del Camp d'Alacant. Alicante, 29.III.82), Alicante, 1983, pp. 229-278.

5 ESTAL, J.M., del, Privilegios otorgados a la ciudad de Alicante, Edición facsímil, Madrid, 1984, p. 21. 
embargo, se reconocen traducidos en privilegios, franquicias, libertades, donaciones, mercedes, buenos usos y costumbres, de forma general en favor de todos los súbditos del lugar; igual sucede en la carta-privilegio de Jaime II fechada el 23 del citado año en favor de la villa de Alicante ${ }^{6}$. No obstante esta generalización, en cuanto a los destinatarios de los derechos y privilegios, no se da en documentos posteriores, donde ya se hace mención expresa de los beneficiados. Así sucede ante el sitio de Lorca el 15 de julio de 1296 o en Mula dieciocho días más tarde7; en el primer caso el rey precisa los mismos "derechos" alterando tan solo el nombre de los destinatarios y manifiesta su voluntad a los predictis hominibus dicte Ciuitatis Cartaienensis et terminorum suorum/, christianis et judeis et sarracenis ${ }^{8}$. Y del mismo modo ocurre tras la toma de Elche por parte del monarca Jaime II mediante documento fechado el 20 de agosto de 1296 en Valencia; en esta ocasión se dirige a los moradores de la aljama en idénticos términos: per nos et nostros confirmamus vobis, predictis sarracenis ville de Elts, terminorum eius et vestris, perpetuo omnia privilegia, franchitates, libertates, donaciones, mercedes, gracias, bonos usus et consuetudines, quas et que habuistis et habetis a novilibus infante dompno Manuel, quondam et comitissa ac Johanne Manuelis usque ad tempora odierna9.

\section{ALCANCE DE LAS CONCESIONES DE JAIME II EN FAVOR DE LA POBLA- CIÓN MUSULMANA}

La presencia castellana en el Reino de Murcia ha permitido a historiadores y juristas trazar en los últimos años un esquema bastante completo del sistema impositivo y garantías jurídicas dirigidas tanto a la población cristiana como a las minorías religiosas sometidas a vínculos reales y señoriales en este marco geográfico ${ }^{10}$.

6 ESTAL, J.M. del, Corpus documental del Reino de Murcia bajo la soberanía de Aragón (12961304/5). Colección de Documentos Medievales Alicantinos, I/1, Alicante, 1985, doc. 120, p. 228 y el traslado notarial doc. 118, p. 223.

7 ESTAL, J.M. del, «Confirmación de Fueros a la ciudad y Reino de Murcia por Jaime ll de Aragón (1296-1304). Anexo documental inédito", en Miscelánea Medieval Murciana, 9, (Murcia 1982), doc. 23, p. 258.

8 ESTAL, J.M. del, "Confirmación de los fueros a la ciudad y reino de Murcia (1296-1304)», op. cit. p. 282.

9 FERRER I MALLOL, M $\mathrm{M}^{\mathrm{a}}$ T., Les aljames sarraïnes de la governació d'Oriola en el segle XIV, Barcelona, 1988, doc. 18, p. 194.

10 Sobre el modelo de derechos y obligaciones del conjunto poblacional bajo dominio castellano es de obligada consulta en primer término el organigrama trazado por el profesor Torres Fontes a partir de un esquema globalizador que intenta redistribuir y definir los impuestos relativos a rentas reales, exenciones y franquezas; véase al respecto TORRES FONTES, J., «Documentos del siglo XIII» en CODOM, vol. II, Murcia, 1969, pp. LVII-LXXVI; y en concreto para el señorío de Alguazas, Murgetana, 17(1947), pp. 81-97. El citado autor ofrece también un clarificador panorama sobre el sistema impositivo directo e indirecto en Actas del IV Simposio Internacional de Mudejarismo: economía (Teruel 1719 septiembre de 1987), Teruel, 1992, pp. 387-393. Sobre el contenido y orígenes de los principales tributos exigibles a la población mudéjar véase POCKLINGTON, R., "Nuevos arabismos en los textos 
Por el contrario, el conjunto de derechos y obligaciones, así como el resto de privilegios concedidos en favor de los mudéjares, bajo dominio aragonés, solo ha recibido un trato puntual en relación con determinadas núcleos de población objeto de estudios monográficos ${ }^{11}$. Es por ello que se impone la necesidad de realizar una aproximación global al contenido y valor jurídico de los derechos y privilegios respetados por Jaime el Justo en favor de contingentes poblacionales minoritarios.

La labor del monarca aragonés consistió, a la luz de la documentación conservada, en regular una serie de instituciones peculiares de la comunidad islámica, que ya habrían sido objeto de interés desde los tiempos de Alfonso X. Esa política real justifica la obligada remisión a los documentos alfonsies para comprender la sensibilidad y el respeto del monarca aragonés hacia la población mudéjar en los primeros años de su presencia en tierras levantinas. Por tanto, y a priori, debe señalarse que no se trata tanto de una creación "ex novo» de derechos sino, por el contrario, de una serie de preceptos resultantes, por un lado de la legislación no derogada en favor de las minorías $^{12}$, por otro, de la propia iniciativa del monarca, quien extrapola a tierras alicantinas y oriholanas soluciones jurídicas ya establecidas en otros ámbitos del reino de Valencia; al propio tiempo, habría también que considerar los privilegios concedi-

alfonsíes murcianos», en Miscelánea Medieval Murciana, 11 (Murcia 1984), pp. 261-293. Finalmente véase RODRÍGUEZ LLOPIS, M., «Población y fiscalidad en las comunidades mudéjares del Reino de Murcia (siglo XV)", en Actas del III Simposio Internacional de Mudejarismo, Teruel, 1984, pp. 39-53.

11 Es este el caso del esquema que sobre derechos y privilegios traza el profesor Hinojosa Montalvo en relación con la morería de Elche (La moreria de Elche en la Edad Media, Serie Estudios Mudéjares, Teruel, 1994). Y de igual modo sucede en relación a Crevillente, debiéndo remitirse el lector a los artículos publicados, por el citado autor, bajo el título "Crevillente: una comunidad mudéjar en la gobernación de Orihuela», en Actas del IV Simposio Internacional de Mudejarismo, Teruel, 1993, pp. 307-318 y «La gestión de la renta feudal en Crevillente durante el siglo XV», en Actas del IV Simposio Internacional de Mudejarismo, Teruel, 1993, pp. 319-338. Ya en un marco mucho más amplio desde el punto de vista temporal y espacial, por cuanto abarca todo el Reino de Valencia, destáquense las aportaciones de FERRER i MALLOL, Ma. T., Organització i defensa d'un territori fronterer. $L a$ Governació d'Oriola en el segle XIV, Barcelona, 1990. Al lector puede serle también de valor instrumental la obra de Burns, quien elabora un estudio minucioso del sistema de derechos, privilegios y exenciones durante el reinado de Jaime I, lo que podría extrapolarse, en determinados aspectos, al ámbito alicantino; véase Medieval Colonialism, Postcrusade Exploitation of Islamic Valencia. Princenton, New Jersey, 1975. En este mismo sentido resulta también de interés la aportación de Hinojosa Montalvo sobre «Señorío y fiscalidad Mudéjar en el reino de Valencia» en Actas del V Simposio Internacional de Mudejarismo, Teruel, 13-15 septiembre, 1990, Teruel, 1991, pp. 105-133.

12 Es este el caso de la documentación de Alfonso $X$ y del Infante don Sancho donde se recogen inumerables preceptos jurídicos que perduran hasta el reinado de Jaime II; situación jurídica que mantenemos al margen de los avatares ocasionados tras las revueltas de los mudéjares durante el reinado de los monarcas castellanos y cuyos efectos negativos hacia los mudéjares tuvieron que ser corregidos en los años inmediatamente posteriores por motivos puramente económicos; y así se mantendrán hasta la llegada del monarca aragonés. Sobre esta documentación véase, ESTAL, J.M. del, Alicante, de villa a ciudad (1252-1490). Colección Documental del Medievo Alicantino, t. III (12521490), Alicante, 1990, doc. 1 al 129. 
dos a los musulmanes por razones de la reciprocidad pactada con los reyes del Norte de África ${ }^{13}$.

\section{DERECHOS RECONOCIDOS EN FAVOR DE LA POBLACIÓN MUDÉJAR}

Las campañas militares llevadas a cabo por el rey Jaime II motivaron, en la mayoría de las ocasiones, un éxodo de la población autóctona por el temor de aquellas gentes a verse desprovistas de su anterior status jurídico; la consideración social de la población mudéjar era el resultado de una política equitativa e igualitaria desarrollada por el monarca Alfonso $X$ el Sabio en los primeros años de su presencia en estas tierras y que se mantuvo posteriormente ${ }^{14}$. El monarca aragonés, sensibilizado ante la situación poblacional, hará una serie de concesiones que, tomadas de la legislación real castellana, devuelvan la confianza a los antiguos moradores de los señoríos ${ }^{15}$ y de las tierras ocupadas ${ }^{16}$.

\subsection{Seguridad personal, de residencia y tránsito}

Aún en el marco general de las concesiones realizadas por Jaime II tras el asedio de los lugares castellanos, merece especial atención destacar que algunas de ellas poseen un contenido especial para la población mudéjar, puesto que constituyen el punto de partida del reconocimiento de su situación particular como minoría religiosa, con sus propias intituciones y costumbres. La libertad, entendida como derecho fundamental de las personas, y la libertad de tránsito para ellas y sus bienes son dos importantes derechos reconocidos por el rey en sendos documentos fechados al inicio de su conquista en los que expresamente el monarca cita a la población mudé-

13 Al respecto véanse los doc.1, 4, 10, 12, 15, 24, 27, 82, 83bis, 91, 116, 131, 132, 145, 147, 148, 150, 156, 157, publicados por ALARCÓN Y SANTÓN, M.A. y GARCÍA DE LINARES, R., Los documentos árabes diplomáticos del Archivo de la Corona de Aragón, Madrid, 1940. Se trata de una serie de documentos traducidos del árabe e intercambiados entre monarcas del Norte de África y Jaime II; en ellos la reciprocidad se eríge en la nota dominante de la política magrebí (e incluso egipcia) en materia de tránsito de personas, establecimiento de lugares para el culto, redención de cautivos y tráfico comercial.

14 Así consta en un documento del citado monarca con fecha de 15 de julio de 1296, por el que se confirman determinados privilegios en favor de la población mudéjar de Cartagena. Véase, ESTAL, J.M. del, Confirmación de los fueros, op. cit. doc. XXI, p. 282.

15 Es este el caso de los privilegiods y franquezas confirmados en favor de los habitantes de Elche; véase TORRES FONTES, J., "Documentos del siglo XIII", en CODOM, II, op. cit. doc. CXXIII, p. 126.

16 Así sucede en relación con el arráez de la Arrixaca de Murcia durante el período de ocupación aragonesa a quien se le garantiza su estancia y posesiones; véase ESTAL, J.M. del, Confirmación de Fueros a la ciudad y Reino de Murcia, pp. 264 y 265/266. Es este también el caso de la confirmación de los fueros y franquicias en favor de los sarracenos del entorno cartagenero (ESTAL, J.M. del, op. cit. p. 282). Igual ocurre con el reconcocimiento de los derechos concedidos anteriormente por monarcas castellanos en favor de los sarracenos de Mula (ESTAL, J.M. del, ibid. p. 260). 
$\operatorname{jar}^{17}$. Buena prueba de la postura tolerante hacia estas gentes es el documento fechado el 4 de mayo de 1296 en el sitio de Orihuela, permitiendo la libertad de desplazamiento y fijación de residencia en tierras alicantinas en los siguientes términos: Rogamos vos [al ra'is de Crevillente] e vos requirimos que los sobredihos moros nuestros/ de Alicant e de los otros nuestros logares que son en Crivillen lexedes yr salvament e seguri pora Alicant/con todas sus cosas e sus bienes ${ }^{18}$. En esta misma línea se pronuncia el monarca en un documento fechado el 19 de mayo de 1296 en favor de los sarracenos de Alguazas, asegurándo su libertad a tots los sarrayns e cascun daquels ${ }^{19}$. $Y$ finalmente un tercer documento otorgado por Jaime II, preludiando el respeto hacia la libertad de los mudéjares, es el otorgado al día siguiente, 20 de mayo, en favor de: todos los Moros del regno nuestro de Murcia de aqualesquier logares sean la sua gracial e bona voluntad ${ }^{20}$.

La actitud tolerante hacia el libre desplazamiento de los mudéjares también es una constante que llega a ser exigida como condición para el mantenimiento de buenas relaciones con los reyes musulmanes del otro lado del Mediterráneo; así se desprende de los tratados firmados en febrero de 1323 con el Abu-l-Fatah Muhammad ibn Qalawn de Egipto o el documento fechado en mayo de 1326 entre Muhammad IV de Granada y Jaime II, en el que se exige el respeto, en distintas esferas, hacia los mudéjares residentes en tierras argonesas ${ }^{21}$.

Otro derecho inherente a la presencia y permanencia de los musulmanes en territorio cristiano es el relativo a la propia seguridad de los mudéjares en tierras alicantinas y oriholanas, y que fué objeto de regulación por parte del monarca Jaime II. No se trata en este caso de la seguridad de tránsito por razón de comercio ${ }^{22}$, sino de la seguridad personal y general reconocida en favor de los habitantes del Reino, esto es cristianos, judíos y sarracenos. El primer documento que hace mención a este derecho personal, en favor de los musulmanes, está fechado el 17 de mayo de 1296 y tiene por objeto garantizar la seguridad de plures Sarraceni, qui fuerunt capti in Çetino et Lorquino, inter quos/sunt aliqui Sarraceni qui sunt de locis uocatis Algustes ${ }^{23}$. Con posterioridad, el 19 de mayo, mantiene el monarca la misma postura hacia los mudéjares del Reino de Murcia ${ }^{24}$. En las mismas fechas, en el documento del 22 de mayo

17 Véase el documento dado ante en el campamento de Lorca el 3 de junio de 1296 (ESTAL, J.M., del, Confirmación de los fueros a la ciudad y reino de Murcia, op. cit. p. 269) y la ratificación ante los muros del castillo de Lorca el 5 de junio de 1296 (ESTAL, J.M. del, Confirmación de los fueros a la ciudad y reino de Murcia, op. cit. p. 271).

18 ESTAL. J.M. del, Alicante, de villa a ciudad, op. cit. doc. 30, p. 175.

19 ESTAL, J.M. del, Confirmación de Fueros a la ciudad y reino de Murcia, op. cit. doc. IV, p. 264.

20 ESTAL, J.M. del, Confirmación de los Fueros a la ciudad y reino de Murcia, op. cit. doc. V, pp. 264/5.

21 ALARCÓN y SANTÓN, A. Los documentos árabes, op. cit. doc. 150, pp. 365-368 y doc. 27 , pp. 55-58 respectivamente.

22 Esta posibilidad es un derecho derivado del mismo ejercicio profesional y que por tanto se exige como condición de reciprocidad para el libre tránsito de personas (mercaderes) y mercancías.

23 ESTAL, J.M. del, Corpus documental, op. cit. doc. 64, p. 175.

24 ESTAL, J.M. del, Confirmación de los Fueros, op. cit. doc. IV, p. 264. 
de 1296, Jaime II se dirige a los mudéjares alicantinos en los siguientes términos: Unde cum Nos assecurauerimus Sarracenos de Alacant et alios qui ad dominum nostrum uenire uellint/in personis et rebuis eorum ${ }^{25}$. Este posicionamiento del rey aragonés se mantiene como símbolo de su política tolerante hacia las minorías religiosas en otros documentos y así se advierte, por ejemplo, en favor de los sarracenos de Petrer el 2 de junio de $1296^{26}$. Las mismas libertades son esgrimidas en el documento expedido para Cartagena desde el sitio de Lorca donde expresamente dice: Uolentes uos uniuersos et singulos homines Ciuitatis Cartagenensis, tam christianos/scilicet quam, judeos ac sarracenos prosequi gracijs et fauore, guidamus et assecuramus uoos per uniuersas ${ }^{27}$. Y esta misma fórmula jurídica en favor del derecho a la libertad de los sarracenos, es reiterada años más tarde, concretamente en 1316, cuando Jaime II vuelve a garantizar la seguridad de los sarracenos, en este caso de la villa y arrabal de Elche, en los siguientes términos: dicimus et mandamus quatenus motus illicitos hominum insurgencium modo predicto vel alias irracionabiliter contra sarracenos predictos sic cohibnbere curetis quod sarraceni ipsi cum bonios eorum sub nostra deffensione securi permaneant a gravaminibus quorumcumque ${ }^{28}$.

\subsection{Derechos reconocidos de carácter judicial y procesal}

Otro derecho reconocido a los sarracenos como consecuencia del respeto hacia sus costumbres es el ejercicio de su propia jurisdicción; estaba basado en particularidades que la comunidad islámica presentaba en materia legal por su carácter confesional. Es por ello que en materia jurisdiccional Jaime II asegura la supremacía de la ley islámica en la resolución de conflictos entre musulmanes, permitiendo no sólo la aplicación de la sunna, sino también la actuación judicial de funcionarios como el "alamín» o el «alcalde de los moros». Este derecho a los propios funcionarios se recoge en un documento fechado el 24 de mayo en favor de las gentes de la villa de Alicante, donde se dice: vobis universis et singulis sarracenis aliame sarracenorum de Alacant, quod in causis vestris iudicemini per alaminum vestrum, iuxta çunnam sarracenorum prout est actenus melius fieri assuetum ${ }^{29}$.

25 ESTAL, J.M. del, Alicante, de villa a ciudad, op. cit. doc. 41, p. 183.

26 ESTAL, J.M. del, Confirmación de los Fueros, op. cit., doc. XI, pp. 271/2.

27 El documento está fechado el 3 de junio de 1296 en el Campamento ante el Castillo de Lorca. Véase ESTAL, J.M. del, «Confirmación de Fueros a la ciudad y reino de Murcia por Jaime ll de Aragón (1296-1304)" Anexo documental inédito, en Miscelánea Medieval Murciana, IX, Murcia, 1982, p. 269.

28 FERRER i MALLOL, M T., La frontera amb l'Islam, op. cit. p. 265.

29 Este primer texto es complementario de otro documento en el que se priva al antiguo defensor del castillo de Alicante de sus competencias jurisdiccionales sobre los sarracenos en los siguientes términos: Mandamus etiam uobis quod dictis Sarracenis in aliquo uos non intrometatis/sed ipsos porcurarj permitattis per Baiulum nostrum de Alacant, situación que es corregida por el monarca al día siguiente reconociendo las competencias del alamín. Sobre este asunto véase ESTAL, J.M. del, Alicante, de villa a ciudad, op. cit. documento de 23 de mayo de 1296 , p. 185 y documento de 24 de mayo de 1296 , p. 186. 
La posibilidad de ejercer los mudéjares su propia jurisdicción se detecta desde los tiempos de Alfonso $X$, e incluso aparece también en el señorío ilicitano del Infante don Juan Manuel. En el primer caso el monarca castellano entre sus medidas legislativas reconoce esta posible jurisdicción para los mudéjares, dejando_constancia de ello en un documento fechado el 19 de mayo de 1257 dirigido a los alcaldes de Cartagena ${ }^{30}$. En cuanto a Elche el Infante don Juan Manuel admitirá la competencia del «alcalde moro" según la ley, exceptuando los derechos del almoxarifatgo que tengo por bien que los jutgue todavía el mío almoxerifí.

\subsection{Derechos de contendio patrimonial y mercantil}

La necesidad que a efectos repobladores suponía la fijación de residencia de los mudéjares en las nuevas tierras sometidas a la soberanía del monarca aragonés comportaba para estas gentes el respeto al disfrute de sus bienes.

Así pues, los bienes de los musulmanes fueron protegidos en las mismas condiciones que su integridad personal, tal y como venía sucediendo desde los tiempos de Alfonso $\mathrm{X}$ el Sabio. Esta situación se pone de relieve en un documento fechado el 5 de junio de 1296 ante los muros del castillo de Lorca Jaime II garantiza y ordena el respeto hacia los bienes y personas de Petrer en los siguientes términos: Nos guidasse et assecurasse ac sub nostra protectione et guidatico speciali/recepisse Sarracenos de Petrer et omnes res eorum per omnia loca dominij nostri, in ueniendi, stando ac etiam redeundo... Quare uobis dicimus et mandamus, quatenus dictis Sarracenis/ predictum guidaticum et assecuramentum obseruetis et contra ipsa non ueniatis nec aliquem contrauenire permittatis /aliqua ratione ${ }^{\beta 2}$. Y en términos análogos se pronuncia un documento fechado en 1301 en favor de los mudéjares de Elda y Novelda ${ }^{33}$.

Pero la protección patrimonial no fue algo novedoso para los súbditos musulmanes del rey Jaime, sino que tiene dos claros precedentes alfonsíes; el primero de ellos en un texto en el que el rey castellano ya habría dispuesto: que todos aquellos que no quieran seguir en nuestra aveniencia, que pueden irse libremente del reino con sus bienes muebles y ajuar propio y que, si en el plazo de treinta dias resolvieron volver a nuestra merced y devoción que no pierdan sus bienes raíces ${ }^{34}$; y el segundo en un documento fechado el 8 de abril de 1272 y que tiene por objeto la repoblación de Orihuela con moros a los que se les permite: que vengan /saluos et seguros con sus mugeres et sus /fiios et con todo lo suyo. Además, conviene señalar que la permisividad del monarca en relación con las propiedades de los mudéjares será un incentivo no sólo para que estas gentes vengan a repoblar sino para que den a su residencia un

30 TORRES FONTES, J., "Fueros y privilegios de Alfonso $X$ el Sabio at reino de Murcia», CODOM, III, op. cit. doc. XL, p. 57.

31 Véase TORRES FONTES, J., «Documentos del siglo XIII», CODOM, II, op. cit. doc. LXXV, p. 69.

32 ESTAL, J.M. del, Confirmación de fueros, op. cit. p. 271.

33 ESTAL, J.M. del, El Reino de Murcia bajo Aragón, op. cit. doc. 196, p. 179.

34 ESTAL, J.M. del, Confirmación de fueros, op. cit. p. 25. 
carácter permanente ${ }^{35}$; esta última circunstancia permitirá asegurar unos rendimientos económicos favorables al nuevo Reino, habida cuenta del carácter imprescindible de unas gentes dedicadas, por lo general, a la agricultura, las manufacturas y el comercio.

La parcela de derechos y privilegios que se aborda en el ámbito comercial es la más escasa en cuanto a documentos se refiere. Las referencias que se conservan se encuandran en la política mercantil general de las tierras levantinas.

La libertad de tráfico comercial es objeto de regulación por parte del monarca aragonés con carácter general para todos los ciudadanos, sin distinción de colectivos. Así se regoge en un documento fechado el 11 de mayo de 1296 en favor de la villa de Orihuela ${ }^{36}$. Días más tarde, el 3 de junio de 1296 en el campamento de Lorca, lo hará en favor de los habitantes de Cartagena ${ }^{37}$. $Y$ con posterioridad para los habitantes de Alicante (según un traslado notarial fechado el 23 de julio de 1296, y realizado por Johannes Raolff). En este último se contiene una aprobación y confirmación hacia uobis dictis hominibus et uniuersitati d'Alacant et successoribus uestris in perpetuum preiuilegis et/franquitates (...) tam per mare scilicet quam per teram, ex omnibus mercibus et aliis rebus uestris ab omni lezda, pedagiis/penso, mensuratico, passatico et ribatico pro dictis rebus et merciius exsoluendis ${ }^{38}$.

El comercio de productos entre musulmanes y cristianos en territorio cristiano va a ser otra de las fuentes de obtención de derechos y privilegios para los musulmanes. El respeto que el rey Jaime II demuestra hacia el ejercicio de estas actividades que los musulmanes venían ejerciendo hasta su llegada comporta el reconocimiento del libre tráfico de mercancías, sujeto, sin embargo, a los derechos y obligaciones de la legislación cristiana. Así, por ejemplo, en un documento dado en favor de los sarracenos de Guardamar, el 20 de febrero de 1298, se les garantiza vobis uniuersis et singulos sarracenis, qui apud locu de Guardamar veneritis /pupilare, quod habeatis mercatum ibidem et perpetum ${ }^{39}$.

El mantenimiento de aquellas actividades comerciales pasaba incluso por la continuidad de la política mercantil marítima con países del norte de África. Esta particular circunstancia, a la luz de la documentación conservada, va a suponer un serio contratiempo en la política del rey aragonés para con los mudéjares, puesto que en muchas ocasiones la concesión de derechos a estas gentes estuvo condicionada por

35 Es este el caso constatado en un documento en favor del respeto hacia los bienes de un sarraceno de Crevillente, con fecha de 13 de mayo de 1296. Véase ESTAL, J.M. del, Corpus Documental de Reino de Murcia, op. cit. doc. 43, p. 156.

36 ESTAL, J.M. del, Privilegios otorgados a la ciudad de Alicante, op. cit. doc. 1, pp. 21/2.

37 ESTAL, J.M. del, Confirmación de fueros a la ciudad y reino de Murcia, op. cit. p. 269. Son varios los documentos en los que esta libertad es garantizada a los mercaderes por Jaime II; véase el apéndice documental de la obra citada y en concreto los docs. IV, V, VI, VIII, IX, X, XII, XXI, XXIII, XXIV, XXV y XXVIII.

38 ESTAL, J.M. del, Alicante, de villa a ciudad, op. cit. doc. 46, p. 187.

39 ESTAL, J.M. del, Corpus documental, op. cit. 162, p. 295. 
las presiones provinientes de los reyes de Berbería, que no dudaban incluso en tomar cautivos con fines coactivos ${ }^{40}$.

En cualquier caso, el monarca aragonés dedica su atención a dos aspectos fundamentales en relación con el tráfico comercial. El primero de ellos es la regulación y concesión de derechos y franquicias sobre el tráfico de mercancías en el interior de la gobernación de Orihuela con carácter general; en segundo lugar el reconocimiento de derechos en favor de la seguridad viaria y de tránsito para mercaderes musulmanes en tierras cristianas.

Los derechos sobre el tráfico comercial, reconocidos en favor de la población musulmana en tiempos de Jaime II, se centran en la regulación de esta materia cuando los intercambios entre musulmanes y cristianos o viceversa se producen en territorio cristiano. De este modo se justifica la seguridad que garantiza el monarca castellano, en beneficio de las relaciones internacionales del momento. Derechos reconocidos son, por ejemplo, la posibilidad de establecer "alhóndigas» y designar cónsules que practiquen integramente sus costumbres y usos ${ }^{41}$. Y esta política será garantizada en aras a unas relaciones de reciprocidad defendidas, incluso, por los reyes del Norte de África ${ }^{42}$.

\section{PRIVILEGIOS REALES Y EXENCIONES EN RELACIÓN CON LAS COMUNIDA- DES MUDÉJARES}

\subsection{Obligaciones militares}

El reconocimiento del derecho a residir y permanecer en territorio cristiano va a obligar a los musulmanes a cumplir unas serie de exigencias en favor del monarca como contrapartida por ese respeto a sus derechos. El reclutamiento forzoso es la prerrogativa real de mayor trascendencia, exigible en virtud de sus incursiones por los antiguos territorios castellanos. La participación de los mudéjares en el ejército del monarca aragonés se da siempre en condiciones de igualdad en relación a los contingentes poblacionales en cuyo seno viven; y así se constata en los documentos conservados en relación con los asedios de poblaciones como Alhama o

40 Sobre este aspecto remítase el lector a los documentos de ALARCÓN, A. y GARCÍA DE LLINARES, R.: Los documentos árabes diplomáticos del Archivo de la Corona de Aragón. Al respecto véase not. 13 .

41 ALARCÓN y SANTÓN, Los documentos árabes, op. cit. doc. 1, pp. 1-3. Documento fechado en Orihuela el 15 de mayo de 1296.

42 ALARCÓN y SANTÓN, A., Los documentos árabes, op. cit. doc. 10, pp. 23/25. Sobre esa misma reciprocidad véase doc. 116, pp. 247-253; este documento es un tratado de paz con el rey de Ifriquiya donde se contiene un rigurosa regulación de las actividades comerciales entre gentes de ambos reinados. $Y$ consúltese el tratado de paz de Jaime II con el rey de Egipto, en análogas circunstancias a los anteriores (op. cit., doc. 145, pp. 334-344). 
Elche, donde la exención de esta obligación afecta por igual tanto a cristianos como sarracenos ${ }^{43}$.

\subsection{Obligaciones fiscales}

\section{A. Tributaciones personales}

La especial consideración que se tiene con la población mudéjar no alcanza a eximirla de determinados impuestos cuya regulación se fecha desde los tiempos de los monarcas castellanos. Así sucede, por ejemplo, en relación al impuesto de la capitación por ser éste un impuesto personal de obligado cumplimiento, e incluso previsto por la propia legislación islámica ${ }^{44}$. De este modo se justifica el hecho de que los mudéjares acatasen, de forma respetuosa, la obligación tributaria que a razón de capite quinque solidos et quatuor denarios anno quolibet in reparacione murorum dicti loci ${ }^{45}$ aportaban desde tiempos castellanos el día de San Martín ${ }^{46}$. Este mismo impuesto ya había sido objeto de regulación durante el reinado de Alfonso $X$ en favor de los mudéjares de las aljamas, huerta u otros castillos del término de Alicante, Nompot (Monforte) Agost, Busot y Aguas, y así queda constancia en la documentación consultada ${ }^{47}$. En este sentido es de señalar que según esta documentación sólo los moros exáricos estuvieran sujetos a la alfenrra, denominada también alfatra ${ }^{48}$.

43 Véase FERRER i MALLOL, Mª.T., La frontera amb /'/slam, op. cit. pp. 228/9, donde se exige la prestación de servicios militares a los musulmanes para el sitio de Alhama; y un documento publicado por la misma autora en favor de los sarracenos de Elche eximiéndoles de participar en el ejército salvo en el caso de invasión del reino de Murcia (FERRER i MALLOL, M…T., Les aljames sarraïnes, doc. 21, p. 196). ESTAL, J.M. del, Alicante de villa a ciudad, op. cit. doc. 5-8, p. 211 y del citado autor véase también los documentos relativos al reclutamiento y exención de esta obligación en favor de los habitantes de distintos lugares del Reino levantino, en El Reino de Murcia hajo Aragón (1296-1305). Colección documental del medievo alicantino, 1/2, Alicante, 1990, doc.128, 146, 160, 209, 247.

$44 \mathrm{Ibn}$ Khaldun, por ejemplo, suministra una justificación religiosa de determinados impuestos conforme al modelo que del sistema impositivo ofrece en la Muqaddima. Véase IBN KHALDUN, Discours sur l'histoire universelle (Al-Muqaddima), trad. par Vincent Monteil, t. II, Beyrouth, 1968, p. 570.

45 ESTAL, J.M. del, Alicante de villa a ciudad, op. cit., doc. 127, pp. 306/7 y doc. 128, pp. 307/8; y véase el precedente en el doc. de 11 de mayo de 1296 en ESTAL, J.M., del, Concesión de fueros, op. cit. p. 263.

46 Como así lo constata la legislación alfonsí del período inmediato anterior. Véase ESTAL, J.M. del, Privilegios otorgados a la ciudad de Alicante, Madrid, 1984, doc. 39, fechado en Córdoba el 30 de junio de 1260, p. 45: Et agora tenemos por bien/et mandamos que todos los moros moradores en Alicant o en la/huerta o en los castiellos del termino d'Alicant los que son axa/riques de los christianos o los que son tenderos o los menestrales que nos/den cada anno un moravedi alffonsi de pecho, et los otros que viven por/su açada o por mar o por otra manera qualsequier, que nos/den cada anno medio morvadi alffonsí.

47 Véanse TORRES FONTES, J., CODOM, IIl, op. cit, documentos LI, LIV, LV fechados en los años 1260 el primero y 1261 los dos segundos; en ellos no solo se regula la cuantía síno la fecha de entrega y la posibilidad de disponer de estos ingresos por parte del Concejo de la ciudad.

48 Véase sobre sus orígenes POCKLINTON, R., "Nuevos arabismos», op. cit. pp. 273/274. 
Además, los derechos reconocidos en favor de la población mudéjar comportan, por lo general y como contrapartida, determinadas obligaciones exigidas a los musulmanes como reconocimiento de la soberanía del monarca aragonés. Este es el caso del impuesto del monedaje, principal tributo por razón de potestad soberana. La exigencia de este impuesto a la población mudejar se contiene en un documento fechado el 24 de abril de 1301 donde se dice: fidelibus suis Christianis, Judeis et Sarracenis/ etc.; y mas adelante: Ideo vobis et singulis vestrum firmiter precipiendo mandamus, quatenus predictis quil, collectores et receptores electi fuerint ad dictum monetaticum colligendum sub forma superius ${ }^{49}$. Con posterioridad, el 27 de abril de 1318 y mediante una Carta dirigida al portant-veus del procurador general del reino de Valencia, Jaime II confirma: Idcirco per presentes concedimus uobis et omnibus et singuis habitantibus in parte regni predicti, tam christianis quam Sarracenis, quod adueniente tempore quo primum Monetaticum post istud nobis tenebimini soluere $e^{50}$; quedando constancia mediante este documento de la necesidad de lograr un equilibrio entre concesiones y exigencias hacia las gentes que permanecieron en territorio cristiano.

Otra obligación tributaria recogida por las fuentes se refiere al pago del impuesto de cena. Así, por ejemplo en 1301 el monarca exige este impuesto de carácter anual a los mudéjares de Orihuela en estos términos: mandamos que el dito dia nos dedes por Cena sicyentos solidos de reales de Murcia ${ }^{51}$ y lo mismo hace el 27 de enero del año siguiente al exigir el mismo impuesto a los: Fidelibus suis Sarracenis de Eltx, etc. ${ }^{52}$; si bien en este último caso el impuesto se exige en su modalidad de tributo periódico y no por hecho circunstancial del paso del monarca y su esposa por aquellas tierras, como se deduce del documento oriholano.

Ahora bien, Jaime II no sólo declara en sus documentos la libertad e inmunidad hacia los singulos sarracenos habitantes et habitatores in dicto loco de Alacant et orta eiusdem ${ }^{53}$, sino que proclama abiertamente una serie de exenciones mediante las siguientes palabras: cum nos exigeremus vel exigi faceremus a sarracenis degentibus in villa seu orta de Alacant alfardam, questiam sive peytam, nos, cum dicti saraceni, tempore quod dictus locus de Alacant era regis Castelle ${ }^{54}$. El mantenimiento de esta situación, anterior incluso al reinado del monarca aragonés, se justifica ante las demostraciones de fidelidad que estas gentes manifiestan hacia el rey aragonés; y por tanto la actitud del monarca debe ser entendida como muestra de gratitud e indulgen-

49 ESTAL, J.M. del, Alicante, de villa a ciudad, op. cit., doc. 70, pp. 222/3.

50 ESTAL, J.M. del, Alicante, de villa a ciudad, (1252-1490). Igualmente véase del mismo autor Colección Documental del medievo Alicantino, t. III (1252-1490), Alicante, 1990, p. 295.

51 ESTAL, J.M. del, Alicante, de villa a ciudad, op. cit. doc. 64, p. 215.

52 Ibid. op. cit. en la nota anterior, doc. 73, p. 227.

53 ESTAL, J.M. del, Alicante, de villa a ciudad, (1252-1490) y Colección Documental del medievo Alicantino, t. III (1252-1490), Alicante, 1990, pp. 307/8.

54 bid. op. cit., en la nota anterior. 
cia hacia los sectores sociales que tradicionalmente eran considerados menos favorecidas: el campesinado y los menestrales ${ }^{55}$.

\section{B. Privilegios y exenciones respecto a los impuestos patrimoniales}

Las garantías y privilegios que ofrece el monarca en relación con las propiedades de los mudéjares permiten al soberano recabar una serie de rentas o tributos que, en última instancia, irían a engrosar las arcas del Reino. Aunque también es cierto que en ocasiones parte de estas rentas o tributos iban a parar a la propia aljama encargada de distribuir las distintas cantidades en aquellas partidas más deficitarias o necesitadas ${ }^{56}$.

En el terreno patrimonial, y desde un punto de vista fiscal, los mudéjares exáricos están exentos ad contribuendum et peytandum in questiis et aliis servitutibus regalibus ${ }^{57}$ y también lo estan de «alfarda»(sic.) ${ }^{58}$. Un precedente sobre este aspecto lo ofrece un texto de 1265 atribuido a don Juan Manuel y dirigido a los moros de Elche donde se dice: $E$ los moros que fuesen en Elig en su término que non den los pechos e los diezmos e los derechos, assi como los davan, nin les pongamos otra costumbre sino la que era ante entre nos e ellos ${ }^{59}$.

La obligación impositiva se suaviza en muchas ocasiones mediante exenciones temporales o permanentes que permiten presagiar un estructurado sistema fiscal. Así lo recogen una serie de documentos que regulan exenciones como el pago de la algarfa ${ }^{60}$ para los moros de Elche ${ }^{61}$ y el impuesto de la

55 Un precedente de este documento es el fechado en 1 de abril de 1324 dirigido al bayle de la Procuración de Orihuela, pero de igual modo dirigido en favor de los compellitis sarracenos agricultores dictos exarichos. Véase ESTAL, J.M. del, Alicante, de villa a ciudad, op. cit. doc.127, p. 306.

56 Vid. FERRER i MALLOL, Ma.T., Les aljames sarraïnes, op. cit. doc. 47, p. 216.

57 ESTAL, J.M. del, Alicante, de villa a ciudad, op. cit. doc. 127, p. 307.

58 ESTAL, J.M. del, op. cit. doc. 128, p. 308. Sobre el contenido de estos tributos en la legislación cristiana y sus precedentes véase POCKLINGTON, R., "Nuevos arabismos en los textos alfonsíes murcianos", en Miscelánea Medieval Murciana, Murcia, 1984, pp. 261-293. Véase sobre su carácter de impuesto por el uso del agua BURNS, J.I., Medieval colonialism, op. cit. pp. 121-137. Sobre la trascendencia del sistema impositivo y su significado para la población islámica andalusí véase "La sofra (sujra)» en Sharq Al-Andalus, 3 (1986), pp. 33-37.

59 TORRES FONTES, J., “Documentos del siglo XIIl», CODOM, II, op. cit. p. 21:

60 No hay referencias en la documentación consultada sobre el contenido de este impuesto. Aunque desconocemos su significado, pudiera tratarse, a tenor de su raíz de procedencia [ga/ra/fa] de un impuesto sobre la extracción del agua para el riego. Sobre el término véase CORRIENTE, F., Dicionario Árabe-Español, Madrid, 1977, p. 553 y voz garafa en Student's Arabic-English dictionary, Beirout, 1986, p. 422.

61 FERRER I MALLOL, Ma. T., Les aljames sarraïnes, op. cit. doc. 22, p. 197. 
tarchana ${ }^{62}$. Estas exenciones sobre impuestos patrimoniales se concedían, bien para propiciar el establecimiento de los musulmanes en estas tierras bien para asegurar su permanencia. Jaime II concedió también a los mudéjares franquicias y privilegios ${ }^{63}$ para el pago de determinados impuestos y así sucede en relación con el cabezaje y alfarda, a tenor de sus posibilidades económicas ${ }^{64}$, o perdona retrasos en el cumplimiento de obligaciones tributarias, como sucede en relación con el almagran que debían los moros de Elche ${ }^{65}$.

Y para concluir debe resaltarse el carácter personal e instransmisible de la obligación triburaria en el cumplimiento de estas imposiciones. Esta circunstancia queda ratificada en un documento real fechado el 21 de junio de 1318 en favor de los sarracenos de Elche ${ }^{66}$; en el se prohibe expresamente la privación de libertad de terceras personas para asegurar y realizar las deudas de sus padres.

62 Impuesto del que no se sabe con certeza sus orígenes y objeto, siendo diversas las interpretaciones sobre su contenido. Para el Profesor Carmona González pudiera tratarse de un antiguo impuesto islámico propio sólo del Norte de África y de al-Andalus que gravaba las fiestas y determinadas diversiones, siendo el perceptor de este impuesto el tarqun (según opinión del autor en base a un trabajo monográfico sobre Ibn al-Hatib de Murcia, en curso de publicación). En el mismo sentido véase el documento citado véase FERRER i MALLOL, $\mathrm{M}^{2}$.T., Les aljames sarraïnes, op. cit. doc.23, p. 197 e HINOJOSA MONTALVO, J., La morería de Elche, op. cit. p. 19.

63 Principalmente moratorias, como sucede en el documento fechado el 21 de abril de 1312 en favor de los musulmanes de Elche. FERRER i MALLOL, Mª.T., op. cit. doc. 38. pp. 208/9.

64 Es este el caso de la franquicia concedida en favor de: quicumque sarracenus barranmius venerit ad dictum locum de Elchio seu termino suo, (FERRER i MALLOL, Mํ. T., Les aljames sarraïnes, op. cit. doc. 26, p. 199).

65 Sobre este impuesto véase BURNS, J.I., Medieval colonisalism, op. cit. pp. 104/7; POCKLINGTON, R., «Nuevos arabismos», op. cit. pp. 281/4 y el doc. 64, p. 231 en la obra FERRER i MALLOL, Mํ.T. (Les aljames sarraïnes, op. cit.).

66 Al respecto véase FERRER i MALLOL, Ma.T., Les aljames sarraïnes, op. cit. doc. 60, p. 228. 